\title{
Authenticity, depression, and deep brain stimulation
}

\author{
Veronica Johansson ${ }^{1,2 *}$, Martin Garwicz ${ }^{1,3}$, Martin Kanje ${ }^{1,4}$, Jens Schouenborg ${ }^{1,3}$, Anders Tingström ${ }^{1,5}$ and \\ Ulf Görman ${ }^{1,2}$
}

Department of Experimental Medical Science, Neuronano Research Center, Lund University, Lund, Sweden

2 Ethics Unit, Centre for Theology and Religious Studies, Lund University, Lund, Sweden

3 Neurophysiology Unit, Department of Experimental Medical Science, Lund University, Lund, Sweden

${ }^{4}$ Department of Biology, Lund University, Lund, Sweden

${ }_{5}$ Molecular Psychiatry Unit, Department of Clinical Sciences, Lund University, Lund, Sweden

*Correspondence: veronica.johansson@med.lu.se

In 2005 the journal Neuron published Mayberg et al.'s (2005) pioneering study on deep brain stimulation (DBS) targeting treatment-refractory major depressive disorder (MDD). Since then a handful of studies, in total encompassing little over 50 patients, have been published (Aouizerate et al., 2005; Jimenez et al., 2005; Mayberg et al., 2005; Kuhn et al., 2007; Lozano et al., 2008; Neimat et al., 2008; Schlaepfer et al., 2008; Malone et al., 2009; Bewernick et al., 2010; Sartorius et al., 2010) and larger trials are underway (Bell et al., 2009). A common ethical concern voiced when DBS is used for a psychiatric disorder such as MDD is that the stimulation specifically targets cognition, mood, and behavior; elements which are closely linked to the patient's personality. Obviously, this holds true also for other antidepressants such as psychotherapy and medication. Apart from that these standard therapies have been of no avail for the patients considered for MDD DBS, one could still ask whether their potential to alter cognition, mood, and behavior, differ - with regard to ethical concerns - from that of DBS. Further, the relevant ethical concern is arguably not what functions the stimulation are intended to alter, as in psychiatric indications, but rather what functions that could be altered by DBS. Unintended alterations of cognition, mood and behaviour could occur as a consequence of both psychiatric and motoric DBS. Thus, potential alterations of personality seem, apart from the historical stigma connected with the former, to be relevant for most DBS indications. A lot of work remains to be done before a comprehensive analysis of these concerns could be presented. Our contribution is to introduce one question relevant to the intersection of DBS, MDD, and the notion(s) of authenticity.
At the heart of the notion of "authenticity" is the idea, with the words of the late British philosopher Bernard Williams, "that some things are in some real sense really you, or express what you are, and others aren't." This idea have not only attracted and been elaborated by philosophers (for further orientation, see Taylor, 1995 or Golomb, 1995), it also appears in our everyday lives. Expressions like "Mary wasn't really herself today" or, "Eric finally showed his true face," points to the notion that not all which we think, feel, or act on express who we really are. Thus, the notion of authenticity can both provide new perspectives to philosophical concerns regarding MDD and DBS, and in addition captures intuitions and beliefs held by many patients (Kramer, 1996; Bolt and Maartje, 2009). In contemporary analytical philosophy, authenticity has usually been employed in discussions on autonomy (Waddell Ekstrom, 1993, 2005), or in theories on "the Self" (Schechtman, 1996, 2004). In addition, authenticity has surfaced in bioethical discussions on issues like sex changes, human enhancement, and treatment of psychiatric disorders. A full account of these diverse interpretations cannot be given here (for instance, solely accounts of the self range from ideas that there are no such thing to ideas of the self as an immortal soul); hence this article is limited to introducing a few key features and their implications.

First one needs to address what the US philosopher Marya Schechtman describes as the characterization question, namely the set of characteristics that makes me the person I am; or, when applied to authenticity, the set of characteristics defining a person's "true self." One answer is suggested by the US philosopher Charles Guignon in the book "On being authentic." He describes this set of characteristics as "the constellation of feelings, needs, desires, capacities, aptitudes, dispositions, and creative abilities that make the person a unique individual" (Guignon, 2004). Guignon's suggestion bears some resemblance to the definition of personality traits according to the DSM-IV of the APA as "enduring patterns of perceiving, relating to, and thinking about the environment and oneself that are exhibited in a wide range of social and personal contexts." The emphasis of "enduring patters" touches on another important feature regarding the true self; does the true self consist of enduring patterns, or is it "constantly shifting and reacting and altering" (Williams, 2002)? However, two other common features of the notion of authenticity diverge from the definition of personality traits according to the DSM.

First, beside the descriptive content the notion of authenticity usually entails a normative claim. To be authentic, it does not suffice to identify the characteristics of one's true self. In addition, the defining set of characteristics must shine through or be expressed in the person's way of living; reflecting on undertakings such as relationships, professional life, and hobbies. Thus, we fail to be authentic when we fail to express some part of our defining characteristics (Guignon, 2004; Schechtman, 2004). Second, these characteristics are often more or less explicitly described as "natural" disposition; implying that this set of inclinations and traits are bestowed on each individual by nature. When these two features combine, authenticity urges the person to live in accordance with this given nature; that which "we are" has a privileged position. Thus, on this view diversions from a person's given nature are morally problematic. Noteworthy, the moral claim of authenticity does not oppose all kinds of alterations of a person; only the changes which distance a person from his or her true selves. Nor is a complete change in personality required for the change to be morally significant; or the rather major changes alluded to within 
psychiatry when talking about personality changes. For being morally significant, it suffices if any of the characteristics that make up your true self is altered.

Given the belief that it would be morally problematic to diverge from who we really are, how could different interpretations of this belief shape our views on MDD and DBS? We will start by introducing one main question, and then briefly sketch some other considerations. Sometimes it seems to be taken for granted that new technology, especially invasive electrodes altering brain function, threaten human values such as dignity, autonomy, quality of life, or a flourishing individual life (these specific examples of "threats" are found in Kuhn et al., 2009); instead of also examining to what extent these techniques could benefit or strengthen these values. Though, we will build an argument regarding authenticity which indicates that the latter may just as well be the case. The group of patients considered for DBS are those suffering from severe, often chronic forms of depression where all standard therapies have failed. Thus, this is our subject matter. So what could be said of these patients? In its severe forms, MDD causes physical symptoms, cognitive impairment, and a diminished emotional reactivity and motivation (Malhi and Bartlett, 2000; SBU, 2004). Thus, the depression greatly impairs the afflicted person's quality of life (Sobocki et al., 2007); it influences personal relationships, work ability, the ability to pursue one's interests etc. (Malhi and Bartlett, 2000; SBU, 2004). Further, beside the well known risk of suicide - one in six of the patients severely affected by MDD take their own life (Malhi and Bartlett, 2000) - there are indications that MDD can cause permanent structural changes in various brain regions, for example hippocampus, amygdala, and prefrontal cortex, as well as an increased likelihood to develop coronary artery disease and type 2 diabetes (WHO, 2001; Kramer, 2005; Krishnan and Nestler, 2008). Nor could these patients, despite common romanticized view of MDD, be considered to benefit from their depressions by increased creativity, thoughtfulness, or by being more insightful (Elliott, 1999, 2003). There might be less severe forms of MDD were such claims could hold some validity, but for this fraction of patients the opposite applies (Kramer, 2005; Ghaemi, 2007).
As previously noted, according to the normative thesis of authenticity we are less authentic if we fail to express some part of our defining characteristics. Conversely, to be fully authentic we must express our true selves in our daily lives, such as relationships, professional life, and hobbies. Considering the impact of MDD described above, it seems obvious that the depression prevents the patients from being and living authentic; i.e., the alterations caused by the depression distance (albeit to what degree varies from case to case) a person from his or her true selves and are thus morally problematic. Accordingly, a successful outcome of DBS could be viewed as a form of liberation since a hindrance for the patient to be and live authentic is eliminated when the depression is vanquished or significantly reduced. Some examples could be an improved health or quality of life, or the ability to return to work, as many of Mayberg's patients managed to do (Egan, 2006); or establishing a relationship. If so, then the DBS treatment would be in accordance with, even promoting, the moral imperative of authenticity. The closer we get to an ideal DBS treatment; with set criteria for patient selection; optimal brain targets identified; and a new generation of electrodes which are more tissue friendly, minute, with precise and directed stimulation fields, and preferably designed to match the intended brain target, the likelihood of this outcome increases (something which in turn may open up for usage in less severe forms of MDD).

Much work lay ahead in identifying and examine other issues where authenticity could provide insights to the ethical implications of DBS for MDD. One fundamental question is whether the depression is a part of, or perceived to be a part of, the patient's personality or not? If the former is the case it would, restricted to an authenticity perspective only, follow that treating the depression is morally problematic - if the alteration distance a person from his or her true self. More importantly, the patient's view on this issue might influence whether he or she will consider DBS, hence empirical studies of this, and similar, questions is warranted. Another issue addresses authenticity, personality changes, and desired treatment outcomes. In a recent article on DBS (Müller and Christen, 2011), it was suggested that the aim of an ethically acceptable treatment, at least prima facie, should be to restore the personality to its premorbid state. Though this suggestion might have an intuitive appeal, and could be defended given a static view of the self, it does seem problematic at a closer look. Most of the patients with MDD considered for DBS have lived with the disorder for years or even decades. Considering the severe impact of the disorder; the depression, as well as the treatment, is not likely to leave the patients unchanged. For instance, at the "brains in dialog on DBS" workshop in Warsaw a participating Parkinson patient gave a telling account of such changes. She described that she after the DBS operation experienced "a third version of me," in comparison to the version of her prior to Parkinson's Disease and the version affected by the disease but prior to the effective symptom relief provided by DBS. Another angle to this question is provided by an observation made by American psychiatrist Peter Kramer in his book "Listening to Prozac." Some of his (previously) depressed patients claimed that, at long last, taking Prozac made them experience their true selves for the first time, even though they, until then, had had another disposition (Kramer, 1996). These accounts point to the problems in assuming that there is such a thing as a premorbid, implicitly authentic, personality to be restored, or, in determining which "version" of the self that is authentic. However, if this is the case does it then make sense to talk about authenticity at all?

We suggest that it does. The concept of authenticity as such provides a means to entangle both philosophical and generally held intuitions regarding normative claims connected to personality changes. A superficial understanding of the concept and its normative implications; for instance, that alterations of cognition, mood, and behavior due to the disorder would be more authentic than comparable alterations caused by the treatment; or that the moral demand of authenticity require that the patient is restored to a premorbid state which obviously is gone forever, could lead us astray. Likewise, the concept is not bound to a dated belief of an authentic self which is given by nature and unchanged by time. Instead, we suggest that the concept of authenticity could be used to capture and analyze the intuition that some alterations of cognition, mood and behavior are ethically objectionable, whereas others are 
unproblematic or even desirable. The concept of authenticity can illuminate ethical concerns regarding changes of a patient's fundamental defining characteristics; how these characteristics vary from patient to patient; and, over the lifespan of a single patient.

\section{ACKNOWLEDGMENTS}

We want to thank Prof. Dan Egonsson, Mats Lindström, and Frits Gåvertsson as well as the participants in the research seminars in ethics, and medical ethics, for valuable comments on earlier drafts. This research project was sponsored by a Linné grant, project number 60012701, from the Swedish Research Council and The Knut and Alice Wallenberg Foundation, project number: KAW 2004.0119.

\section{REFERENCES}

American Psychiatric Association (APA). (1994). Diagnostic and Statistical Manual of Mental Disorders, 4th Edn, Washington, DC: American Psychiatric Association.

Aouizerate, B., Martin-Guehl, C., Cuny, E., Guehl, D., Amieva, H., Benazzouz, A., Fabrigoule, C., Bioulac, B., Tignol, J., and Burbaud, P. (2005). Deep brain stimulation for OCD and major depression. Am. J. Psychiatry 162, 2192.

Bell, E., Mathieu, G., and Racine, E. (2009). Preparing the ethical future of deep brain stimulation. Surg. Neurol. 72, 577-586

Bewernick, B. H., Hurlemann, R., Matusch, A., Kayser, S., Grubert, C., Hadrysiewicz, B., Axmacher, N., Lemke, M., Cooper-Mahkorn, D., Cohen, M. X., Brockmann, H., Lenartz, D., Sturm, V., and Schlaepfer, T.E. (2010). Nucleus accumbens deep brain stimulation decreases ratings of depression and anxiety in treatment-resistant depression. Biol. Psychiatry 67, 110-117.

Bolt, I., and Maartje, S. (2009). Psychopharmaceutical enhancers: enhancing identity? Neuroethics 2, 103-111.

Egan, D. (2006). The New Lobotomy? 'Deep brain stimulation' Tested at UBC as Depression Cure. The Tyee: A Feisty One. Available at: http://thetyee.ca/ News/2006/10/26/DBS/

Elliott, C. (1999). A Philosophical Disease: Bioethics, Culture, and Identity. New York: Routledge.
Elliott, C. (2003). Better Than Well: American Medicine Meets the American Dream. New York: W.W. Norton. Ghaemi, S. N. (2007). The Concepts of Psychiatry: A Pluralistic Approach to the Mind and Mental Illness. Baltimore: Johns Hopkins University Press.

Golomb, J. (1995). Problems of Modern European Thought: In Search of Authenticity. New York: Routledge

Guignon, C. B. (2004). On Being Authentic. New York: Routledge.

Jimenez, F., Velasco, F., Salin-Pascual, R., Hernández, J. A., Velasco, M., Criales, J. L., and Nicolini, H. (2005). A patient with a resistant major depression disorder treated with deep brain stimulation in the inferior thalamic peduncle. Neurosurgery 57, 585-593; discussion 585-593.

Kramer, P.D. (1996). Lyssna till Prozac. Falun: Bokförlaget Natur och Kultur.

Kramer, P. D. (2005). Against Depression. New York: Viking.

Krishnan, V., and Nestler, E. J. (2008). The molecular neurobiology of depression. Nature 455, 894-902.

Kuhn, J., Gaebel, W., Klosterkoetter, J., and Woopen, C. (2009). Deep brain stimulation as a new therapeutic approach in therapy-resistant mental disorders: ethical aspects of investigational treatment. Eur. Arch. Psychiatry Clin. Neurosci. 259, 135-141.

Kuhn, J., Lenartz, D., Huff, W., Lee, S., Koulousakis, A. Klosterkoetter, J., and Sturm, V. (2007). Remission of alcohol dependency following deep brain stimulation of the nucleus accumbens: valuable therapeutic implications? J. Neurol. Neurosurg. Psychiatr. 78, 1152-1153.

Lozano, A. M., Mayberg, H. S., Giacobbe, P., Hamani, C., Craddock, R. C., and Kennedy, S. H. (2008). Subcallosal cingulate gyrus deep brain stimulation for treatment-resistant depression. Biol. Psychiatry 64, 461-467.

Malhi, G. S., and Bartlett, J. R. (2000). Depression: a role for neurosurgery?. Br. J. Neurosurg. 14, 415-422.

Malone, D. A., and Dougherty, D. D., Rezai, A. R., Carpenter, L. L., Friehs, G. M., Eskandar, E. N., Rauch, S. L., Rasmussen, S. A., Machado, A. G., Kubu, C. S., Tyrka, A. R., Price, L. H., Stypulkowski, P. H., Giftakis, J. E., Rise, M. T., Malloy, P. F., Salloway, S. P., and Greenberg, B. D. (2009). Deep brain stimulation of the ventral capsule/ventral striatum for treatment-resistant depression. Biol. Psychiatry 65, 267-276.

Mayberg, H. S., Lozano, A. M., Voon, V., McNeely, H. E., Seminowicz, D., Hamani, C., Schwalb, J. M., and Kennedy, S. H. (2005). Deep brain stimulation for treatment-resistant depression. Neuron 45, 651-660.

Müller, S., and Christen, M. (2011). Deep brain stimulation in Parkinsonian patients - ethical evaluation of cognitive, affective, and behavioral sequelae. $A J O B$ Neurosci. 2, 3-13.

Neimat, J. S., and Hamani, C., Giacobbe, P., Merskey, H., Kennedy, S. H., Mayberg, H. S., and Lozano, A. M. (2008). Neural stimulation successfully treats depression in patients with prior ablative cingulotomy. Am. J. Psychiatry 165, 687-693.

Sartorius, A., Kiening, K. L., Kirsch, P., von Gall, C. C., Haberkorn, U., Unterberg, A. W., Henn, F. A., and Meyer-Lindenberg, A. (2010). Remission of major depression under deep brain stimulation of the lateral habenula in a therapy-refractory patient. Biol. Psychiatry 67, e9-e11.

SBU. (2004). Behandling av depressionssjukdomar: En systematisk litteraturöversikt, Volym 1-3. SBU-rapport nr 166/1-3, Stockholm: SBU.

Schechtman, M. (1996). The Constitution of Selves. Ithaca: Cornell University Press.

Schechtman, M. (2004). Self-expression and self-control. Ratio 17, 409-427.

Schlaepfer, T.E., Cohen,M.X., Frick, C., Kosel,M., Brodesser, D., Axmacher, N., Joe, A. Y., Kreft, M., Lenartz, D., and Sturm, V.(2008). Deep brain stimulation to reward circuitry alleviates anhedonia in refractory major depression. Neuropsychopharmacology 33, 368-377.

Sobocki, P., Lekander, I., Borgström, F., Ström, O., and Runeson, B. (2007). The economic burden of depression in Sweden from 1997 to 2005. Eur. Psychiatry22, 146-152.

Taylor, C. (1995). The Ethics of Authenticity. Cambridge, MA: Harvard University Press.

Waddell Ekstrom, L. (1993). A coherence theory of autonomy. Philos. Phenomenol. Res. 53, 599-616.

Waddell Ekstrom, L. (2005). Alienation, autonomy, and the self. Midwest Stud. Philos. 29, 45-67.

WHO. (2001). The World Health Report 2001 - Mental Health: New Understanding, New Hope. Available at: http://www.who.int/whr/2001/en/index.html

Williams, B. A. O. (2002). Truth and Truthfulness: An Essay in Genealogy. Princeton, NJ: Princeton University Press.

Received: 24 January 2011; accepted: 09 May 2011; published online: 23 May 2011.

Citation: Johansson V, Garwicz M, Kanje M, Schouenborg J, Tingström A and Görman U (2011) Authenticity, depression, and deep brain stimulation. Front. Integr. Neurosci. 5:21. doi: 10.3389/fnint.2011.00021

Copyright $(\odot 2011$ Johansson, Garwicz, Kanje, Schouenborg, Tingström and Görman. This is an open-access article subject to a non-exclusive license between the authors and Frontiers Media SA, which permits use, distribution and reproduction in other forums, provided the original authors and source are credited and other Frontiers conditions are complied with. 